\title{
COVID19 and increased mortality in African Americans: socioeconomic differences or does the renin angiotensin system also contribute?
}

\author{
Michael Doumas $\mathbb{D}^{1} \cdot$ Dimitrios Patoulias ${ }^{1} \cdot$ Alexandra Katsimardou $\mathbb{D}^{1} \cdot$ Konstantinos Stavropoulos $\mathbb{B}^{1} \cdot$ \\ Konstantinos Imprialos ${ }^{1} \cdot$ Asterios Karagiannis $^{1}$
}

Received: 8 May 2020 / Revised: 24 June 2020 / Accepted: 7 July 2020 / Published online: 15 July 2020

(c) The Author(s), under exclusive licence to Springer Nature Limited 2020

\section{Introduction}

The dawn of the new decade is marked by the emergence of the novel coronavirus SARS-CoV-2, whose spread has resulted in the COVID-19 pandemic, having already affected millions of individuals and resulted in hundreds of thousands of deaths worldwide $[1,2]$. While the pandemic situation is constantly evolving, alarming signals have arisen during the past few weeks from the United States of America, which now represents the world's most affected country, as disproportionally higher infection and mortality rates in African-Americans compared to other races were reported in some states [3, 4]. After these initial reports that raised public awareness, most states gradually started sharing data regarding confirmed cases and deaths by race. Most of them have reported higher infection rates in African-Americans, although data regarding confirmed COVID-19 cases by race are largely incomplete [5]. Furthermore, based on current estimates, it is calculated that overall African-Americans suffer from a 2.4 and 2.2 times higher mortality rate when compared to Whites and Asians or Latinos, respectively [6, 7].

The first thing that needs to be addressed is whether this phenomenon is actual or COVID-19 was spread in states with a relatively higher African-American population. Available data suggest that the mortality rate is indeed higher, even when adjusted for the African-American population in each state in most cases. In Illinois, for instance, $14 \%$ of the population which is African-Americans accounts for $36 \%$ of confirmed COVID-19 deaths. Similarly,

Michael Doumas

michalisdoumas@yahoo.co.uk

1 2nd Propedeutic Department of Internal Medicine, Aristotle University, Thessaloniki, Greece in Michigan $43 \%$ of deaths concerned African-Americans who represent $14 \%$ of the state's population [7]. However, more data is eagerly needed on this topic: first of all from every state, and second for specific counties as well, since the population is not evenly divided by race within each state.

The higher mortality rate in African-Americans raises questions about the underlying mechanisms behind these racial disparities. Several known mechanisms might be implicated, including increased comorbidities, inequalities in healthcare access, and socioeconomic factors. However, we propose that another mechanism might be also implicated: the renin-angiotensin system.

\section{Comorbidities}

Cumulative evidence from China and Italy, two countries being at the epicenter of COVID-19 pandemic before the US, suggests that, besides age, comorbidities such as cardiovascular disease (mainly ischemic heart disease and stroke), hypertension, diabetes mellitus, chronic respiratory disease and atrial fibrillation increase the risk of mortality among the affected patients [8, 9]. Indeed, hypertension increases the risk for the development of acute respiratory distress syndrome (ARDS) by $82 \%$, while diabetes mellitus augments the corresponding risk by $134 \%$ [10]. Hypertension is more prevalent among African-Americans, even at earlier ages, compared to other races, while control rates remain poorer [11, 12]. Besides, it has been previously demonstrated that black patients with diabetes mellitus feature significantly greater odds for insufficient glycemic control, compared to nonHispanic whites [13], while they also have a significantly higher rate of in-hospital complications, compared to nondiabetic white patients with hyperglycemia. However, no statistically significant difference for adverse in-hospital outcomes is observed, when 
white and black patients with diabetes are compared [14]. Of note, African-American women have been shown to have a greater risk for stroke, heart failure and end-stage renal disease (ESRD) compared to white women, whereas African-American men feature greater risk for heart failure and ESRD, but lower risk for coronary artery disease compared to white men [15]. Collectively, that evidence might partially explain the greater burden of COVID-19 pandemic among black patients.

\section{Socioeconomic factors and healthcare access}

Socioeconomic factors could also play a significant role. While billions of people worldwide are encouraged to implement teleworking, for many African-Americans it is not a matter of choice due to working in essential industries, with less than $20 \%$ being able to work from home, rising the possibilities for exposure and infection [16]. Social distancing has been so far recognized as the most effective measure of spread attenuation [17]. However, the family structure differs in African-Americans, as family members share closer bonds and are more likely to share accommodation, resulting in close contact among the elderly and the youth, who are also more unlikely to conform to social distancing. In fact, the spread of the disease in China and Europe during the previous months led several people to assume that African-Americans are "immune" to COVID19 , resulting in significant misinformation on this issue with obvious consequences. Indeed, a recent report revealed that many African-Americans lack critical knowledge about COVID-19 and have not changed their daily routine [18].

Given that the unemployment and uninsurance rates for African-Americans are higher than average, their access to healthcare facilities is significantly disabling and probably resulting in under detection of less serious cases [19]. Another significant factor in this field is the relatively higher mistrust of African-Americans in the healthcare system [20]. The limited access to combined with the mistrust at the healthcare system might result in significant delays in seeking assistance, and thus increased mortality rates in African-Americans.

However, Latinos share some of the above-mentioned socioeconomic characteristics, at least partly, although early reports suggest that they exhibit lower mortality rates compared to African-Americans, as it has already been mentioned [7].

\section{Renin-angiotensin system}

We should also highlight the potential role of renin-angiotensin-aldosterone system (RAAS) blockers use among black patients. Low plasma renin activity, associated with a salt-sensitive phenotype, has been documented for black patients compared to white individuals [21]. The hallmark ALLHAT trial, which enrolled a significant proportion of black patients, demonstrated for the first time the superiority of chlorthalidone compared to lisinopril in the prevention of surrogate endpoints, namely stroke, combined coronary artery disease and cardiovascular disease and heart failure [22]. Thus, according to the 2017 American College of Cardiology/American Heart Association Hypertension Guidelines, initial antihypertensive treatment in black adults with hypertension but without heart failure or chronic kidney disease, including those with diabetes mellitus, should include a thiazide-type diuretic or a calcium-channel blocker (CCB) [23]. However, a recent meta-analysis pooling data from a total of 38,983 hypertensive black patients did not reveal a significant difference between RAAS blockers and the rest antihypertensive drug classes regarding the odds for hard endpoints, except for stroke; patients treated with RAAS blockers featured an over 50\% increase in the odds for stroke, compared to those treated with diuretics or CCBs [24]. Anyway, the fact is that the use of RAAS inhibitors is less common in African-Americans compared to Caucasians [25].

Based on the pathophysiologic background underlying SARS-CoV-2 infection, several preclinical studies raised concerns on the safety of RAAS blockers in patients with documented infection; however, there is no hard evidence to support the discontinuation of these agents, especially in high-risk patients [26]. For this reason, several scientific societies, such as the European Societies of Hypertension and Cardiology (ESH, ESC), the Heart Failure Society of America, the American College of Cardiology and the American Heart Association (HFSA/ACC/AHA) issued statements that advised towards the continuation of RAAS blockers for indications that are known to be beneficial [27-29] Furthermore, recent evidence suggests that their use not only cannot be associated with increased risk of COVID-19 or increased risk of in-hospital mortality, but also it has been associated with improved survival, although with limitations [30-32]. Of note, no differences have been reported among ACE inhibitors and angiotensin receptor blockers regarding major clinical outcomes (severity of SARS-CoV-2 infection, mortality) [33, 34]. Therefore, it has to be elucidated whether the lower usage rates of RAAS blockers among black patients could partially contribute to the observed racial disparity in the severity of SARS-CoV-2 infection.

It has been demonstrated that SARS-CoV-2 invades human alveolar epithelial cells through the angiotensin converting enzyme 2 (ACE2) receptor, leading to downregulation of ACE2 expression and rapid progression to ARDS [35]. It would be therefore interesting to know whether black patients 
exhibit greater genetic susceptibility to SARS-CoV-2, even though the genetic basis of ACE2 expression in different populations remains largely unknown [36]. What is more, specific ACE2 gene polymorphisms have been correlated with essential hypertension, atrial fibrillation, major adverse cardiovascular events, reduced left ventricular ejection fraction and increased left ventricular mass, mainly in Asian, and Caucasian populations [37-40]. Therefore, one could speculate that there might be a vicious circle between increased susceptibility to SARS-CoV-2, cardiovascular comorbidities and final development of severe infection, which has to be proven. Unfortunately, there are no data until now regarding the interconnection between ACE2 polymorphisms and cardiovascular disease development in African-American populations. Existing gene databases, such as the Million Veteran Program including over 825,000 Veteran participants, could serve as a valuable tool towards this direction [41].

\section{Conclusion}

Undoubtedly, COVID-19 pandemic will continue to strain health care systems worldwide. As our understanding regarding the pathophysiologic mechanisms implicated in this disease further evolves, we may be able to better acknowledge demographic, genetic, behavioral and health factors that are associated with increased mortality in specific vulnerable groups, such as African-Americans.

\section{Compliance with ethical standards}

Conflict of interest The authors declare that they have no conflict of interest.

Publisher's note Springer Nature remains neutral with regard to jurisdictional claims in published maps and institutional affiliations.

\section{References}

1. Zhu N, Zhang D, Wang W, Li X, Yang B, Song J, et al. A novel coronavirus from patients with Pneumonia in China, 2019. N Engl J Med. 2020;382:727-33.

2. Dong E, Du H, Gardner L. An interactive web-based dashboard to track COVID-19 in real time. Lancet Infect Dis. 2020;20: P533-534.

3. Thebault R, Ba Tran A, Williams V. The coronavirus is infecting and killing black Americans at an alarmingly high rate. The Washington Post. https://www.washingtonpost.com/nation/2020/ 04/07/coronavirus-is-infecting-killing-black-americans-an-ala rmingly-high-rate-post-analysis-shows/?arc404=true. Accessed 10 April 2020.

4. Levenson E. Why black Americans are at higher risk for coronavirus. CNN. https://edition.cnn.com/2020/04/07/us/corona virus-black-americans-race/index.html. Accessed 10 April 2020 .
5. Godoy M, Wood D. What do coronavirus racial disparities look like state by state? NPR. https://www.npr.org/sections/healthshots/2020/05/30/865413079/what-do-coronavirus-racial-dispa rities-look-like-state-by-state $? \mathrm{t}=1591524493188$. Accessed 7 June 2020.

6. John Hopkins University. Racial data transparency. https://corona virus.jhu.edu/data/racial-data-transparency. Accessed 7 May 2020.

7. APM Research Lab. The color of coronavirus: COVID-19 deaths by race and ethnicity in the U.S. https://www.apmresearchlab.org/ covid/deaths-by-race. Accessed June 7th 2020.

8. Wu Z, McGoogan JM. Characteristics of and important lessons from the coronavirus disease 2019 (COVID-19) outbreak in China: summary of a report of 72,314 cases from the Chinese Center for Disease Control and Prevention. JAMA. 2020;323:1239-42.

9. Onder G, Rezza G, Brusaferro S. Case-fatality rate and characteristics of patients dying in relation to COVID-19 in Italy. JAMA. 2020; https://doi.org/10.1001/jama.2020.4683.

10. Wu C, Chen X, Cai Y, Xia J, Zhou X, Xu S, et al. Risk factors associated with acute respiratory distress syndrome and death in patients with coronavirus disease 2019 Pneumonia in Wuhan, China. JAMA Intern Med. 2020; https://doi.org/10.1001/jama internmed.2020.0994.

11. Virani SS, Alonso A, Benjamin EJ, Bittencourt MS, Callaway CW, Carson AP, et al. Heart disease and stroke statistics-2020 update: a report from the American Heart Association. Circulation. 2020;141:e139-e596.

12. Lackland DT. Racial differences in hypertension: implications for high blood pressure management. Am J Med Sci. 2014;348:135-8.

13. Egede LE, Gebregziabher M, Hunt KJ, Axon RN, Echols C, Gilbert GE, et al. Regional, geographic, and racial/ethnic variation in glycemic control in a national sample of veterans with diabetes. Diabetes Care. 2011;34:938 LP-943.

14. Fayfman M, Vellanki P, Alexopoulos AS, Buehler L, Zhao L, Smiley D, et al. Report on racial disparities in hospitalized patients with hyperglycemia and diabetes. J Clin Endocrinol Metab. 2016;101:1144-50.

15. Shen Y, Shi L, Nauman E, Katzmarzyk PT, Price-Haywood EG, Yin $\mathrm{P}$, et al. Race and sex differences in rates of diabetic complications. J Diabetes. 2019;11:449-56.

16. Job flexibilities and work schedules-2017-2018 Data from the American Time Use Survey. U.S. Bureau of Labor Statistics. https://www.bls.gov/news.release/pdf/flex2.pdf. Accessed 14 April 2020.

17. Omer SB, Malani P, Del Rio C. The COVID-19 pandemic in the US: a clinical update. JAMA 2020; https://doi.org/10.1001/jama. 2020.5788 .

18. Wolf MS, Serper M, Opsasnick L, O'Conor RM, Curtis LM, Benavente JY, et al. Awareness, attitudes, and actions related to COVID-19 among adults with chronic conditions at the onset of the U.S. outbreak: a cross-sectional survey. Ann Intern Med. 2020; https://doi.org/10.7326/M20-1239.

19. Gaffney A, McCormick D. The affordable care act: implications for health-care equity. Lancet. 2017;389:1442-52.

20. Musa D, Schulz R, Harris R, Silverman M, Thomas SB. Trust in the health care system and the use of preventive health services by older black and white adults. Am J Public Health. 2009;99:1293-9.

21. Alderman MH, Cohen HW, Sealey JE, Laragh JH. Plasma renin activity levels in hypertensive persons: their wide range and lack of suppression in diabetic and in most elderly patients. Am J Hypertens. 2004;17:1-7.

22. The ALLHAT Officers and Coordinators for the ALLHAT Collaborative Research Group. Major outcomes in high-risk hypertensive patients randomized to angiotensin-converting enzyme 
inhibitor or calcium channel blocker vs. diuretic: the antihypertensive and lipid-lowering treatment to prevent heart attack trial (ALLHAT). JAMA. 2002;288:2981-97.

23. Whelton PK, Carey RM, Aronow WS, Casey DE Jr, Collins KJ, Dennison Himmelfarb C, et al. 2017 ACC/AHA/AAPA/ABC/ ACPM/AGS/APhA/ASH/ASPC/NMA/PCNA Guideline for the prevention, detection, evaluation, and management of high blood pressure in adults: a report of the American College of Cardiology/American Heart Association task force on clinical practice guidelines. Hypertension. 2018;71:1269-324.

24. Palla M, Ando T, Androulakis E, Telila T, Briasoulis A. Reninangiotensin system inhibitors vs. other antihypertensives in hypertensive blacks: a meta-analysis. J Clin Hypertens. 2017;19:344-50.

25. Gu A, Yue Y, Desai RP, Argulian E. Racial and ethnic differences in antihypertensive medication use and blood pressure control among US adults with hypertension: The National Health and Nutrition Examination Survey, 2003 to 2012. Circ Cardiovasc Qual Outcomes. 2017;10:e003166.

26. Vaduganathan M, Vardeny O, Michel T, McMurray JJV, Pfeffer MA, Solomon SD. Renin-angiotensin-aldosterone system inhibitors in patients with Covid-19. N Engl J Med. 2020;382:1653-9.

27. ESH Statement on COVID-19. ESH. https://www.eshonline.org/ spotlights/esh-statement-covid-19/. Accessed 7 June 2020.

28. Simone G. Position statement of the ESC council on hypertension on ACE-inhibitors and angiotensin receptor blockers. ESC. https://www.escardio.org/Councils/Council-on-Hypertension(CHT)/News/position-statement-of-the-esc-council-onhypertension-on-ace-inhibitors-and-ang. Accessed 7 June 2020.

29. HFSA/ACC/AHA Statement Addresses Concerns Re: Using RAAS Antagonists in COVID-19. ACC. https://www.acc.org/la test-in-cardiology/articles/2020/03/17/08/59/hfsa-acc-aha-sta tement-addresses-concerns-re-using-raas-antagonists-in-covid-19. Accessed 7 June 2020.

30. Mancia G, Rea F, Ludergnani M, Apolone G, Corrao G. Renin-angiotensin-aldosterone system blockers and the risk of COVID-19. N Engl J Med. 2020;382:2431-40.

31. Zhang P, Zhu L, Cai J, Lei F, Qin JJ, Xie J, et al. Association of inpatient use of angiotensin converting enzyme inhibitors and angiotensin II receptor blockers with mortality among patients with hypertension hospitilized with COVID-19. Circ Res. 2020;126:1671-81.
32. Meng J, Xiao G, Zhang J, He X, Ou M, Bi J, et al. Reninangiotensin system inhibitors improve the clinical outcomes of COVID-19 patients with hypertension. Emerg Microbes Infect. 2020;9:757-60.

33. Li J, Wang X, Chen J, Zhang H, Deng A. Association of renin-angiotensin system inhibitors with severity or risk of death in patients with hypertension hospitalized for coronavirus disease 2019 (COVID-19) infection in Wuhan, China. JAMA Cardiol. 2020; https://doi.org/10.1001/jamacardio.2020.1624.

34. Giorgi Rossi P, Marino M, Formisano D, Venturelli F, Vicentini M, Grilli R. The Reggio Emilia COVID-19 Working Group. Characteristics and outcomes of a cohort of SARS-CoV-2 patients in the Province of Reggio Emilia, Italy. MedRxiv. 2020; https:// doi.org/10.1101/2020.04.13.20063545.

35. Cheng H, Wang Y, Wang GQ. Organ-protective effect of angiotensin-converting enzyme 2 and its effect on the prognosis of COVID-19. J Med Virol. 2020; https://doi.org/10.1002/jmv. 25785.

36. Cao Y, Li L, Feng Z, Wan S, Huang P, Sun X, et al. Comparative genetic analysis of the novel coronavirus (2019-nCoV/SARSCoV-2) receptor ACE2 in different populations. Cell Discov. 2020;6:11.

37. Liu C, Li Y, Guan T, Lai Y, Shen Y, Zeyaweiding A, et al. ACE2 polymorphisms associated with cardiovascular risk in Uygurs with type 2 diabetes mellitus. Cardiovasc Diabetol. 2018;17:127.

38. Zhang Q, Cong M, Wang N, Li X, Zhang H, Zhang K, et al. Association of angiotensin-converting enzyme 2 gene polymorphism and enzymatic activity with essential hypertension in different gender: a case-control study. Medicine. 2018;97: e12917-e12917.

39. Patel SK, Wai B, Ord M, MacIsaac RJ, Grant S, Velkoska E, et al. Association of ACE2 genetic variants with blood pressure, left ventricular mass, and cardiac function in caucasians with type 2 diabetes. Am J Hypertens. 2012;25:216-22.

40. Wang SX, Tao T, Fu ZQ, Xie XZ, Wang H, Wang YT. Polymorphisms of angiotensin-converting enzyme 2 gene confer a risk to lone atrial fibrillation in Chinese male patients. Chin Med J. 2013;126:4608-11.

41. Gaziano JM, Concato J, Brophy M, Fiore L, Pyarajan S, Breeling J, et al. Million Veteran Program: a mega-biobank to study genetic influences on health and disease. $\mathrm{J}$ Clin Epidemiol. 2016;70:214-223. 